PLEASE NOTE! THIS IS SELF-ARCHIVED VERSION OF THE ORIGINAL ARTICLE

To cite this Article: J. Tuomas Harviainen, Maria Ekström \& Jukka Ojasalo (2018) Tactical Service Failure: A Case Study on Public Funding as a Marketing Issue, Journal of Nonprofit \& Public Sector Marketing.

doi: $10.1080 / 10495142.2018 .1452826$

URL: https://doi.org/10.1080/10495142.2018.1452826

This is a final draft version of the original article. 


\title{
Tactical Service Failure:
}

\section{A Case Study on Public Funding as a Marketing Issue \\ J. Tuomas Harviainen \\ Management and Organization \\ Hanken School of Economics}

\author{
Maria Ekström \\ Jukka Ojasalo \\ Laurea University of Applied Sciences
}

Abbreviated title:

Public Funding as a Marketing Issue 
Abstract. This article analyzes the ways in which public sector service providers may use service delivery failure as a way of securing resources. In tactical service failure, an organization tactically delivers non-adequate service, so as to project a media image of being harmed by its funding cuts. Analyzing this process enables new insight into both public funding and provider to funder (P2F) marketing and selling. This research uses a single case study method to confirm the existence of the phenomenon first detected through long-term media analysis. To explore the single case, the authors interviewed a former city official who participated in tactical service failure processes and their marketing. The article shows how and why service providers may opt for this tactic, as well as the potential gains and pitfalls of utilizing it. It also provides new insight into how media connections are used to influence public funding decisions.

Keywords Funding, Monopsony selling, Provider-to-funder selling, Public services, Service failure, Service Quality.

\section{INTRODUCTION}

"Co-operating with media during a challenging change situation within the basic health care sector: During a radical change of the working practices within basic health care in a middlesized Finnish municipality (during the years of 2010-2014), the co-operation between media and the health care service provider was strategic and target-oriented. The core communication was based on facts that addressed issues that we define as tactical service failures: delay in service availability, narrow range of services, costly services and service impact. To create urgency in the decision-making process, communication was sometimes provocative and always upfront. The change process was made visible to citizens and at the same time helped the decisionmakers. Unfortunately, there were some tensions between the health care provider and the 
politicians and the visibility in media declined. How this affected the funding opportunities remains to be seen." (Email interview data, 2015, translated by [first author])

In this article, based on a case study and media-analysis, we use theories from selling and marketing to analyze the way in which public services' funding may be tied to their intentionally performing less than adequate service. Unlike corporations that rely on investor trust or on customer loyalty gained as a result of high-quality services and customer satisfaction (Caruana, 2002), public service providers may sometimes benefit from customer perceptions of inefficiency or inferior service quality. This is because such an image may get them extra funding, especially during times of crisis. The situation is often the result of a blurry view on who is their primary customer. A customer has the power to choose and not to choose, when paying directly for e.g., health care. When the paying customer is not the consumer of the service, the actual consumer of the service has another position and other "sales techniques" should be used (e.g., Fountain, 2001). An example of this situation is a municipality paying for the health care of its citizens (the service's consumers, to whom we in this article refer to as the primary customers of a service). This article discusses the situation where those consumers need to be leveraged by the public service provider to put pressure on the customer who pays their bill.

It has been long recognized that the primary market of public sector service providers may well be the oversight bodies that decide on their funding (Nutt \& Backoff, 1993; Nutt, 2006). Yet, surprisingly enough, the ways in which such organizations use marketing techniques to affect those oversight bodies remain understudied. This may partially be because such organizations have in the past been able to use coercive techniques of customer management, with little need for marketing (Nutt \& Backoff, 1993). Nowadays, however, the market is open to competition in an unprecedented manner, and public sector service providers have to justify their costs - and 
sometimes even their existences. At the same time, they rarely have sufficient marketing budgets or personnel of their own.

A core expectation of public service is that it is equal for all. In truth, prioritization nevertheless has to be made very often, as resources are never infinite (Aberbach \& Christensen, 2005). Expectations of equality and quality therefore become image issues. The image of a service provider largely arises from its organization, culture and members, the type of service it provides, as well as its service quality and market segments (Normann, 2001). In many public services, the importance of the provided service can come to question, as commercial competitors are able to provide higher quality. Likewise, the primary customers' experiences with the provided service may not reach the ears of those who pay for the service. Primary customers refer to consumers of a public service. It is in this situation where tactical service failure (TSF), an intentional media exposure of a large-scale failure, enters the scene. It arises from the thought that the actual users of the service are not able to sufficiently influence those who pay for it all (e.g., municipality governments), and more drastic methods are needed. Here, we discuss the TSF process, situations that foster such an institutional begging-threatening combo, and the advantages and risks connected to such marketing and selling behavior.

“We realized public funding alone wasn't enough to get the job done.”

"The health care sector [and its development or funding cuts] became a weapon used between political groups."

It is an old adage in selling that even a great product does not sell itself, but needs someone or something able to sell it. Publicly produced or procured services to citizens are even more difficult to provide without an encounter between the service provider and customer. This can especially 
be seen in the context of public sector service providers. For example, public health care is seen as cumbersome, slow and inefficient when compared to its more high-priced private cousins. The public medical services do not however need to be sold, as the demand seems to exceed supply. The result is that the public provider fails in one crucial criterion - efficiency - and that is what matters. The brand of the public service provider is unclear and bad, sometimes simply just because it is a public service (Bok, 2001; Van de Walle, 2016). It becomes the option of mostly for those who cannot pay for the service offered by the private sector. In other words, it is perceived as "welfare" rather than standard municipal service, and that is a sure way to continuously lose public funding.

Because the lack of sufficient financial support is what causes the troubles in the first place, the downward spiral eventually feeds itself. When combined with inaccurate or insufficient metrics (e.g., patient turnover time instead of the health of the patients sent home), it can become fatal for the organization. In sales terms, this can be considered a situation where the primary customer loses its trust in the service provider and starts to just look for significant discounts, not more value. With the concept of "value" being very ambiguous within the public sector, it is easy for the funders to turn to profit-based metrics instead. They have to justify their spending decisions for both the public and to each other, and make claims on the value their investments into particular services will supposedly create (O'Flynn, 2007). This mismatch between purpose and measurement is far from optimal from the side of the actual service provider. Feeling shortchanged and unappreciated, providers may turn to displays of problems. They use a cultural branding strategy (see Oswald, 2015) that broadcasts their challenges while highlighting that the ways in which their work is measured is imprecise, outdated - and the problems are the fault of external forces. 
"At first the politicians were enthusiastic about the external funding, but as time went by, people became envious that we were able to organize the extra teams, without which real development could not have been done. ... So after a while, our public core funding started to see corresponding cuts, and [resources that had been already promised were] instead denied from us."

"The officials were saying [during budget planning] that we were inefficient and could not handle our financial planning. So we had to fight that with public facts. ... Then, they forbid us from publishing the assessment results."

Public sector service providers rarely focus on financial profit. Instead, they are either costefficient, they fulfill community obligations towards citizens (aiming at a "social profit"), or are both cost-efficient and socially oriented (Austin, Stevenson \& Wei-Skillern, 2006; van Helden \& Reichard, 2016). The key problem lies in the fact that the social profit (also known as, e.g., social impact) is extremely hard to measure, especially on the level of a singular operator's influence. For example, metrics for schools and universities can include the number of graduates and the grades with which they graduate, but can rarely take into account skills such as a continued interest in learning or self-improvement. Grades can, however, be given for very different amounts and qualities of work. Likewise, even shared tests like SATs can become something that turns into a focus of training in a manner that disrupts the learning of everything else. It is furthermore a very different thing to analyze e.g., the effectiveness of public health service by time spent per patient, by money spent, or by how many more healthy years a senior citizen gets.

As a result of this problem with metrics, many public service providers are likely targets of repeated funding cuts. They therefore must convince others of their relevance, despite the challenge of the metrics. Because the situation resembles very closely, in some factors, other 
forms of selling, we consider it too to be a kind of sales process. We call it provider-to-funder selling (P2F). It is a calculated (or sometimes just desperate) type of pitching. Most of the time this selling takes place through normal channels such as formal reports and positive media publicity. In times of drastic cuts, however, the tone dramatically changes and TSF steps in. The pitch turns into one of three types, all of which seek the same thing: sufficient funding. Firstly, the provider may use already happened large-scale failures as case examples on why it needs more money (or the cancellation of impending cuts). Secondly, it may threaten that future failures will take place if the funding is not secured. And thirdly, it may even intentionally arrange an artificial, visible service failure, in order to use that failure to demonstrate that its needs are critical.

All the three forms include a calculated risk. On the one hand, if the organization does not resort to such tactics crucial funding can be denied, as its need is not seen well enough. On the other hand, the organization may just end up feeding the image of itself as obsolete, incompetent, and rightfully deserving to be put down. TSF is essentially a balancing act between need and risk. Organizations therefore try and select only some functions where they fail, in order to be able to still show enough core competences to keep themselves at least partially credible as providers of service.

Through our analysis, we answer the research question why is it sometimes financially advantageous for public service providers to fail at providing adequate service for their customers, and how do they sell that failure in order to get more funding? With it, we contribute to the study of not only public service failure research (James et al., 2016; Van de Walle, 2016), but also questions of reverse marketing (e.g., Leenders \& Blenkhorn, 1988), the relationship between public organizations and the media (e.g., Liu \& Horsley, 2007), and especially discourses on internal marketing within the public sector (e.g., Ewing \& Caruana, 2000). 
This article is structured as follows: after the methodology section, we summarize the findings of this study. Then, we analyze three key points: the tactics of TSF, how service failure is used in selling a service's importance, and the sales pitch of failure itself. In discussion, we outline the functions and implications of tactical service failure, and then conclude with remarks on public sector's provider-to-funder marketing. These are done in the context of illustrative quotes from the interviews, showing how each point follows from both existing theory and the field data.

\section{METHODOLOGY}

The initial data for this article were collected through a two-year long media analysis. It was found as a target of opportunity, when [the first author] noticed that news of funding cuts tended to be immediately followed by media exposure of crucial failures in service, always blaming the aforementioned cuts for the problems. During the two-year period, [first author] systematically observed 15 major Finnish news sources in order to locate more instances of similar reports, assisted by [the second author, third author] and several colleagues. Emphasis was based on large-scale cases that were shared on social media (e.g., Facebook, Twitter), which were systematically noted in the data collection as particularly significant. In our opinion those best represent the fact that tactical service failure cases appear to be intentionally tailored to create maximal visibility. In the current day and age, this means viral spreading in social media.

The media analysis revealed the existence of the phenomenon of TSF, but a case study was needed to understand its nature and to conceptualize it at higher level. After that, abductive reasoning (Magnani, 2001) was used in the analysis to further explain and understand the nature of TSF, in other words to develop explanatory hypotheses for the central phenomenon of the research. Haig (2005) distinguishes between phenomena detection and theory construction as part of abductive method. Both evidence from empirical material as well earlier theories can be 
combined for constructing a new theory. According to Reichertz (2007), abductive inferencing is an attitude towards the data and towards one's own knowledge, data are to be taken seriously, and the validity of previously developed knowledge is to be queried. The result is a theory which fits the surprising facts or solves the practical problem which arises from these (Kelle, 2007).

Since many types of service failures exists, with highly differing scopes and consequences, we decided to document those that were a) connected in the media to a present or impending lack of sufficient resources and b) were attributed to systemic challenges. In Van de Walle's (2016) terms, on cases of either failure by neglect (by the funders, not by the organization itself) or failure by design (insufficient resources). A total of 18 probable cases of TSF were identified and analyzed during that time. We believe that while those were located within Finland and in the context of Nordic welfare societies, the same processes take place in also other types of communities, in possibly less easily observable but equally strong forms.

The identification stage was followed by a confirmation phase, where we sought evidence of the tactic in action. In this, we followed Ketokivi and Choi's (2014) observation that case research can be effectively used also for theory testing, particularly in situations that are highly context-bound. We felt that even as the theory to be tested was currently formed just as a hypothesis ("a marketing viewpoint explains why public service providers make some failures public"), it was dependent on the Nordic public service funding model, and thus highly suitable for verification by a case study. Using a single case, we sought to prove the existence of the phenomenon, and to provide roots for further research into the topic. We chose a single case methodology because the concept is introduced and has not yet reached the status of a theory that can be used to compare different cases (cf. Flyvjberg 2004). Stake (2005) refers to singular cases as entities that have some kind of boundaries. They are usually seen as the "one" and it is specific. In this article, we are concentrating on a case (municipality), but at the same time we are aiming at 
finding a new definition on a phenomenon, which cannot be seen as a singular case. On the other hand Stake (2005, p. 445) defines a case study as an instrumental one, if the aim is to "provide an insight into an issue". This is what we sought to do.

We therefore located and interviewed two former city officials whose organization, a service development unit in a mid-size Finnish municipality, had utilized this identified tactic in the public healthcare sector. A preliminary set of questions was sent to Interviewee A and answered by email in 2015, after which a live interview was organized in 2016. A second informant was located in 2017 and interviewed on the phone. Both interviews followed a focused, semi-structured form in which elaborative questions were asked (as per Kvale \& Brinkmann, 2014). The first live interview lasted 64 minutes, the second one 33 minutes. The results were completely transcribed and coded by [second author], after which the coding was checked and confirmed by the two other authors, both of whom had extensive expertise in the use of qualitative research methods. Each of the three authors first analyzed the data separately, after which it was discussed together by all three authors.

\section{FINDINGS}

Based on a triangulation of the interviews and the media analysis, we constructed a process formulation of how TSF usually takes place. We illustrate it here with anonymized quotes from the interviews. Unless noted otherwise, all quotes here come from the first live interview. Several details have been omitted due to ethical proofreading, which requires that in sensitive topics, the researcher should always assume that the results end up read by parties hostile to the informants, should they be identifiable (Lee 1993). Likewise, our number of informants is limited, because of the whistleblower nature of the information we needed to gather. We believe that the results nevertheless show that TSF exists and how and when it is applied. 
Our central finding was the identification of the phenomenon in question as an actual practice, thus confirming our hypothesis that had been constructed based on the media analysis: TSF, as a marketing phenomenon, exists. It is based on a tactical use of failure and media exposure. We also identified situations in which the practice would probably arise, and the way in which people in charge of using it considered it a last-ditch effort, but also something that arose from a consistent earlier media relationship (a fact emphasized especially by Interviewee B). Without earlier efficient media relations and visibility, it is very difficult to utilize TSF, as it requires both marketing expertise and good, reliable media contacts. In the following sections, we analyze and elaborate the findings in the context of existing theory.

Next, the nature and function of TSF is briefly explained and illustrated based on the empirical data of this study. Figure 1 shows the main entities in the context of public service government, provision, and consumption, as well as the role and function of TSF in marketing in marketing of public service.

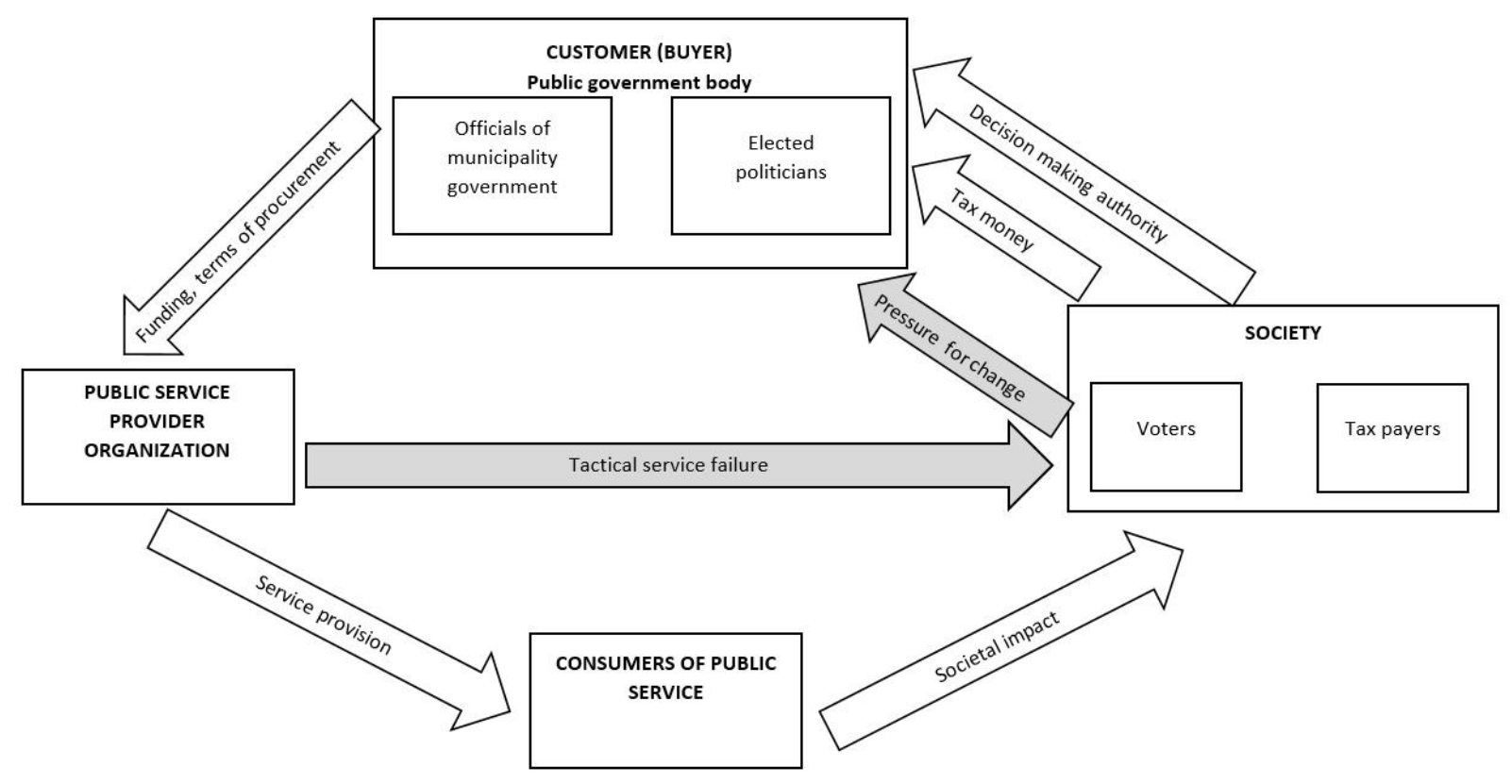

Figure 1. Tactical service failure in P2F marketing of public service 
Four main entities exist in the context of public service government, provision, and consumption. They are the buyer, public service provider organization, consumers of public service, and society. In a democratic society voters elect the politicians to represent them in the public government, thus giving them the decision-making authority. Similarly, taxpayers give funding to their representatives to cover the cost of public spending.

The buyer is the public government body that makes the buying decision of the public service. In our case study it is the municipality, however it can be any other body of the public government authorized for public procurement of certain service, product or solution. Elected politicians hold the highest decision making authority in the public government. However, at operational level, the officials working for public government bodies have a major role in the decision-making in the procurement of public services. The government body negotiates with the public service provider organization about the terms and details of the public service being procured. The funding of the public service provider organization comes from the public government body functioning as a buyer. Our data suggest that the negotiations may in certain circumstances be dictation with little understanding or concern about the realities in which the public service organization functions. This is what triggers the public service provision organization to use TSF.

The public service provider organization takes care of the daily production and delivery of the public service. In our empirical case, the service organization provided health and wellbeing services to the citizens of the municipality.

Consumers of public service are those who use the public service. Consumers of public service are often voter and taxpayers as well, thus having several roles in our model. However, this is not always the case. Small children consume health care and educational services, and visitors from 
foreign countries can use library during their stay. Indeed, not all public service consumers are voters and tax payers of the society. The consumption of public services causes the societal impact. The impact is that the society has citizens who are healthier, more educated, and have better quality of life, for example.

Our data shows that the need for TSF emerges from the contradiction between the buyer and provider of public service about the funding and terms public service being procured. The buyer of the public service is a monopsony in our case study, namely a municipality. This makes the bargaining position most difficult to the public service provider organization. It easily leads into a situation where the service provider does not have adequate resources to fulfill its obligations. Still, the blame of bad service is allocated to the service provider, not to the representatives of the buyer. The data of this study show that in such a desperate situation the public service provider can use TSF in marketing its service, and to legitimate the quantity and quality of the service, and fundamentally even its own the existence. TSF represents a radical and direct short cut between the public service provider and society to manipulate the public opinion into favorable for the needs and objectives of the service provider. By purposely and systematically affecting the public opinion the public service provider creates pressure from the society to the elected politicians and officials of the public government body responsible for procurement of the public service. The public pressure is created to change the funding conditions and other terms of the procurement to be more favorable to the public service provider. TSF is explained in more detail in the following deductive analysis based on our empirical data and also findings from earlier research.

\section{ANALYSIS}

In our study, we identified the existence of TSF with media analysis. Then, with an empirical case study we examined the role and function of TSF in marketing of public service (Figure 1). Next, 
we further our analysis on TSF with abductive reasoning, based on both the empirical material in hand as well as earlier research literature.

\section{The tactics of non-adequate service}

"We made calculations that [showed that] if we did not get the funding, [a large amount of time] by the staff would go into basic customer service and not requested [service] development, as it was supposed to.... And we made that public."

Wilson et al. (2006, p. 105) define customer gap as the difference between customer expectations and customer perceptions about service. For most service providers, it is optimal to provide service that falls somewhere between what customers desire and what they find adequate. Going below adequate creates complaints, whereas systematic exceeding of expectations raises the bar of what customers consider to be the baseline. For certain public service providers, however, going below adequate can be an effective strategy. If the service provided is too good, the demand will exceed supply even more. It is the paradoxical situation where a service provider does not want more customers and even starts a process of demarketing, or in other words, the reduction of demand (see Kotler \& Levy, 1971). This is especially true of service providers the metrics of which are insufficient to measure what they actually provide, and/or those that are under the threat of significant funding cuts.

The logic behind the move is that many organizations in the public sector have to operate in a service ecology in which their service propositions are not known well enough, especially not by those deciding on their funding. These are ecologies which the service providers themselves cannot control or possibly even influence. They thus turn to what means of influence they have, by selling their need. As described by Jobber and Lancaster (2009, p. 240), preparations for sales negotiations usually feature four elements that determine their success: availability of options for 
each party, the information held by each, the need for recognition and satisfaction, and external and internal pressures upon each party.

For many public sector service providers, this is a very dangerous combination. The funders are expected to make required budget cuts, they want public recognition for doing those, and they try to accomplish it in the least unpopular way. Simultaneously, the quality of information that they have on each service and its providers can be both obsolete and misleading. For example, it is quite possible that the councilman reducing library funding has not stepped inside a library for 20 years, and has never used that library's online services either. He thus thinks that all that happens there is the handing over of worn-out old novels, or that the librarian's work is about cleaning dust from shelves. To fight this, certain organizations have started to broadcast their troubles in order to convince funders of their importance, as we found out in our media study. In a way, they outsource their P2F sales function to journalists who will dramatize the misery of their customers. They intentionally do not perform as well as they could, e.g., by not using overtime to compensate for staff reductions. The point of this move is that those in charge of the providers' situations have to face the consequences of their decisions. It is a risky tactic, but it sometimes pays off.

In some sense, this is a normal result of the logic that if budget cuts are too large, their results may become visible, and the provider should make sure that they really do. In other words, that remaining staff should not try and make up for the damage done, but rather refrain from extending their service. This makes it visible that the cuts have had an effect and it protects the staff from exhaustion caused by overworking. Tactical non-adequacy, however, takes things one stage further. In it, sympathy is sought by producing to the customers the image that the staff is doing all that it can to keep up the level of service quality. Yet despite their good intent, they simply cannot keep doing so, because of the cuts. While part of that projection is probably real especially if the service provider actually has a healthy work ethic and good, loyal and professional 
workers - but parts of it are carefully orchestrated performances. These performances are furthermore tailored to fit different target audiences and different funder types.

Jobber and Lancaster (2009, p. 12) list key traits of successful salespersons. Many of them describe a tactically non-adequate service provider as well. In using TSF, the organization has to be determined, disciplined, and resilient, or the tactic will not work. The organization has to know how much of failure it will be able to sustain without permanent damage to its service provision ability. Likewise, it has to know about the risks of reputation damage and how far to take that line, because reputational failure can be just as dangerous as actual failure (Bromley, 2000). This is especially true for non-profit service providers (Sarstedt \& Schloderer, 2011; Schloderer, Sarsted \& Ringle, 2014). The ability to communicate is obviously important as well. Without it, the message of an impending doom will not reach the funders and the whole process will just appear to be a failure on the service provider's part. This is however something that the organization will have to learn (or re-learn), because the existence of a situation where tactical non-adequacy is needed clearly points out that the provider's needs were not communicated well enough to the funders before or in due time in the first place.

That last criterion is particularly interesting: many public sector service providers are usually what they are precisely because they exist to provide empathetic, people-oriented things such as health care, teaching and welfare. They likely even have formal visions and missions centered on doing good. In desperately seeking funding through failure, they have to temporarily bracket that organizational empathy. Caring too much about their immediate customers would make them less able to utilize this tactical advantage to a sufficient extent. In other words, the non-adequacy has to be productified through public statements by customers as well as by the service providers themselves. This approach nevertheless seems to be just as useful for an empathy-bracketing daycare center as it is for seeking military funding. It appears that when in need, caregivers can 
be just as ruthless in marketing as the members of governmental monopolies on violence are. Next, we analyze the way in which providers perform this P2F sales pitch.

\section{Selling through failure}

"Reporting concrete cases seemed to work more effectively. ... We made sure we always had data to back up our argumentation."

"The fault fell on the officials ... We collected customer feedback and made sure the customers were on our side."

Public actors can and do underperform in order to get more funding. In doing so, the actors are threatening that the public value will be deteriorating because their delivery of the services will have inferior quality. We build here on the idea of creating public value introduced by Moore (1995). The sales process is different in our example because the custom concept in TSF is diffuse and the creation of value is difficult to address. How public value and customer value are interrelated is important to address, but goes outside the scope of this article. We draw on the thoughts of Viio and Grönroos (2016), who state that the sales process should "strategically match...the buyer's situation". In our example, the buyer is society itself, represented by e.g., states and municipalities.

Selling is first and foremost a promise that is either kept or not. In tactical non-adequacy, it is publicly made. It is then only kept to the extent that the service provider thinks should be considered reasonable under the current funding. The idea is to create a public relations pathway, in which the provider's lack of an ability to sufficiently provide its duties is transported to those who decide on its resources. As described by Schloderer, Sarstedt and Ringle (2014), the affective dimension (e.g., likeability) of a non-profit organization seems to influence supporting 
behaviors such as volunteering and donations more than does the cognitive dimension, which includes competence. We believe, however, that as far as public funding is concerned, the cognitive dimension holds more power. This is because of the contractual nature of public finance - the funding agency requires a sufficient level of service in return for its support. There are some similarities with B2B marketing where the seller has to face a more complicated buying process. The process of buying includes different levels of selling, in the form of convincing different organizational levels that a certain service is worthwhile. Dealing with these levels resembles dealing with a buying center (Webster and Wind, 1972) in classic B2B selling theories. Should the service provider fail the negotiated contract, the service promise made by the funder to the community through its financial support of that service provider fails, too. This opens a window of opportunity for a desperate service provider.

The service provider aims its failure-threat marketing for one special segment: the funder's need to deliver what it has promised to its citizens. The service provider, stuck in a monopsony, turns the tables at a crucial moment so that it in turn has a monopoly. In response to the single buyer's (the funder's) market, a single seller market too is created. By doing so, the provider shows that its fate is linked to that of the funder, and its failure will be the funder's failure as well. This P2F marketing is based on knowing the primary customer's need and threatening not to fulfill it. At the same time, the service provider is also marketing its problems to the wider public, its other customers included, in an apologetic manner: "We would love to serve you better, but..." It attacks what Nutt (2006) calls the "fickle oversight" of public service - the fact that elected officials must cater to various stakeholder groups, and may bow even at the pressure of one of those.

This is public relations work par excellence, as close to its propaganda roots as possible: deliberate, planned and sustained, used to indoctrinate and to create loyalty. Therefore, customer needs are at the center of the planning, but utilized as a threat instead of being served. This can 
be considered market targeting to the extreme: the organization is showing that it cannot serve the other customers (e.g., patients), in order to show that its primary customer - the funder - has to keep paying for its services at a good enough price. The company objective of that service provider is of course to keep serving those other customers (e.g., patients, library patrons). To get the money to do that, however, it must temporarily neglect their needs. The service provider simultaneously has to position itself in the market so that it is obvious that the fault does not lie within that organization itself, but rather those who finance it. It does this with a special type of sales cycle, the TSF pitch, to which we turn next.

\section{The sales pitch of failure}

"So the CEO started lobbying and made [local media] into a partner and stakeholder, and we were quite open about things ... so in the end, we actually got the money, but like after about six more months of pointless grinding."

"We made sure we were in the media every week or so."

As we have explained above, the process of securing future funding in a crisis situation is, for a public sector service provider, very much like a sales pitch. The funders are its primary targets. In other words, while it may provide forms of service to others, those who in the public eye are thought of as its "customers" (e.g., a community hospital to citizens), they are not the ones who pay the bills. The same way as a salesperson in a B2B situation needs to reach the person who actually decides on the customer's use of money (such as the CFO), the P2F sales pitch has to reach the funders in e.g., municipality government. As noted above, the challenge in the situation is that the provider works in a monopsony market: there is only one customer, that customer either buys or not, and is able to define the "price" at its own rate. Therefore, P2F selling is about selling value propositions and seeing how much can be haggled. At the core is the threat that if the key 
customer pays too little, it too will suffer, as the lower value it purchases will prevent it from fulfilling its own value propositions (expectations and obligations) to others.

This leads to a tricky balance of fear, in which few of the key rules of selling apply, but the principles of it still very much do. For example, of the criteria listed by Moncrief and Marshall (2005) as central characteristics of modern selling, some become redundant while others are emphasized: customer retention is utterly crucial, and customer deletion practically impossible. Therefore, customer relationship management becomes extremely important. However, in a situation requiring tactical non-adequacy, it is likely that the customer relationship has already gone sour. Customer databases are not usually necessary, because of the monopsony, unless the service provider wants to play dirty and has inside information on e.g., individual city council members.

Customer data management is not necessary either, except in cases where it could be utilized to show that the organization is being judged with unsuitable metrics. The TSF process itself is about marketing the service, just with an atypical touch to it. This in turn makes the organization to want to emphasize its ability to solve problems, should it be allowed to function as a system (e.g., by showing that cuts here will lead to fatal inefficiency, and how it can work wonders if no big cuts are made). And, finally, tactical non-adequacy is about saying that if the lowest bidding "price" is not met, the providers can neither satisfy the needs of the customer, nor help offer more value.

The decision is therefore framed for the funder through both economic and social purchase criteria. If they do not buy the service from this particular provider, they will face social consequences and a loss of reputation. Likewise, if they make the decision on too tightly fixed economic criteria, they will not get the value that they need, and again lose reputation. Used against elected politicians, this is in theory a remarkably efficient pitch, as long as those politicians 
are not able to hide behind a crowd of peers (James et al., 2016). In practice, such hiding is exactly what happens, so more drastic measures may be used to respond to this. Like Blackwell, Miniard and Engel (2003) point out, the decision process towards buying starts with need identification or problem awareness. What the tactical non-adequacy seeks to establish is the situation where e.g., politicians need to openly acknowledge the problem, and must thus initiate a purchasing process. The tool for accomplishing this is a final push tactic, the unavoidable media exposure. It functions as an aggressive sales proposition: "if you don't buy, we'll make sure you pay for it in massive reputation damage". Whether it fails or succeeds is a combination of pitching skill, optimal media exposure, and risk assessments made by the politicians it targets.

\section{DISCUSSION}

Cases of these media exposure tactics are plentiful, in addition to our single case example here. In Finland for example, several such topics arose during 2013-2016, identified in our media study. For example, a day after large government funding cuts to the mobile police were announced, a major newspaper ran an article on recent increases in speeding violations and DUls, obviously pointing to the need of a sufficient police presence to counter this. A major hospital in Southern Finland had front-page coverage of the length of their emergency room waiting lines. When a large city near the capital had to cut down school funding, particularly in special needs education, the crisis immediately entered public discourse. And when the Finnish Meteorological Institute had to reduce the money they spent on pollen detection and reporting, they made at once very sure that it too was on the Internet and the newspapers - with allergic people worriedly spreading the news on Facebook. In each case, the coverage sparked public debate on what exactly are appropriate targets for funding cuts, and in many cases netted the organizations significant concessions. And remarkably, not in a single case was the publicity of underperformance problematic for the service providers themselves. It appears that the tactic is indeed working, and when used rarely enough, sells quite well. This is the central part of the pitch: 
"We stated openly that if funding was not provided, we could not do certain [very necessary] things.... Our CEO used this as a weapon, ... that even if it was required by law, we could not provide the service."

It forces the monopsony buyer to publicly state that it was a mistake to cut the funding, or to explain why they chose to cut it, possibly even in career-destructive terms. It is therefore important to reach elected officials' reputations with the pitch - while it may well be the official in the municipality government who decided on the cuts initially, they tend not to suffer from reputation damage the same way as elected politicians do. Therefore, the plan is to touch those who would suffer. Even if the elected officials do not sit on the money, they are the ones who more often than not have the final say on how it is used, and they are the ones who stand to lose the most through reputation damage. This is a factor of what Walton and Hume (2012) consider the controllability aspect of public service failure attribution: the public must think that it was the politicians who had control over the factors that led to the failure. A smart public sector service provider thus gets the politicians, through media, to force the other stakeholders' hands.

"We first and foremost communicated about the situation to the citizens of the municipality ... so as to remind people that the changes were being made not for organizational advantage, but to [keep the central focus on] customer needs and their connection to the city's resource situation ... what we considered the sort of [financial] crash. ... We decided that we would not try and explain, but rather utilize a realistic perspective on why we were enacting the changes."

To introduce business thinking and concepts in the public sector context is nothing new. We are aware of the discourse of new public management where business concepts and tools are introduced in the public sector setting in order to drive efficiency and quality (e.g., Hood, 1991). 
The novelty in this article is to scrutinize especially how the public sector sales function differs from the private sector setting. As noted by both our interviewee and the respondents of Parker, Kaufman-Scarborough and Parker (2007), public service providers may have to market the importance of their activities. They do this first and foremost to their own "management" above the people who decide their funding. Part of this is the marketing of the providers' employees' skills, rather than the service itself. One key way for doing so is through service visibility, the strategic revealing of interesting parts of a service process to customers in order to make them more aware of the quality of service that they are receiving (Harviainen, 2014). In essence, it is a way of altering the value proposition process through explanation and exposition.

Tactical non-adequacy follows the same principle, but intentionally reveals pain points in the service instead, preferable of the migraine type, points that are associated with funding cuts. It can thus be seen as an organizational revelation of production processes, in which the provider creates an image of potential service quality. It then states that it cannot reach (or preserve) that quality level within the current limitations or with the future threats that the organization is facing. Through this dissonance, it seeks to secure the pressure needed to exert commitment from the funders, either directly or (more commonly) with the pressurizing help of public opinion. The pitch can be summed up as "we are essentially great, and people can see that - but if you force us down, we will drag you down with us."

"The city owned [the primary media channel], so [the key politicians wanting funding cuts to take place] used that to totally cut off our access to it. That created a media blackout on our situation."

Centrally, tactical non-adequacy is not a method that can be repeated several times over. It is a desperate last-minute plea, and to do it one time too many turns the organization into a beggar in 
the eyes of the funders. It is then no longer a service provider, but a money-demander, and thus needs to be cut off. This is a kind of sales forecast, where the management sees that without this one crucial deal, a point of no return as far as funding goes will be crossed. To not engage in TSF at that point seems like doom for the organization (or at least some of its key members' careers), so it appears worth the risk.

On the other hand, if a public organization makes a successful TSF pitch, it will be forced thereafter to really perform much better. What it effectively buys reciprocally in return with the successful sale is that it now lives on borrowed time. It will be put down (or at least its managers will be fired) if the funders do not see significant results in return for their investment. Likewise, if the TSF attempt fails, similar things are likely to happen, because the publicity will then not protect those who were in charge of the media influence operation. Whether public service providers can prosper enough under these tight parameters remains to be seen.

\section{CONCLUSIONS}

"We had discussed beforehand who would say what [to the media], so that we would be systematic [in our communication]."

This article has discussed and presented the existence and processes of tactical service failure, as well as shown how a marketing perspective explains certain phenomena in public sector funding. At first glance, public sector service providers may seem very different from companies in the ways they sell their services. Companies' first duty is to create profit, hopefully with both ethical means and environmentally sustainable methods. Public sector service providers cannot do that. At the core, however, they both seek to survive and prosper and to attract the best possible people. If a company cannot create profit, it goes bankrupt and perishes, and a public sector organization with its funding cut is just as dead. Therefore, they both sell their services, in 
the same ways, just mostly to different directions. It is, at the end, a question about who pays for the purchases, not about who uses the actual service.

We believe that this connection requires further study. Public sector organizations, no matter whether they provide administrative, productive or supportive service, are in truth just as salesoriented as their commercial compatriots. Their marketing strategies and especially internal audiences are just different (Ewing \& Caruana, 2000). The way they sell may look strange to the untrained eye, but it is not at all any more different than the ways in which sales tactics may have to differ from one product to the next, between B2C, C2C, and B2B, or especially between selling solutions, products, and services. To improve the ways in which the public sector functions, we have to understand how it approaches its own types of sales, not think that it is not selling anything. No one is as efficient at a hard sell as is a public sector service provider whose funding is about to be cut. This is something from which also commercial service companies could - and should - learn a lot.

\section{ACKNOWLEDGEMENTS}

No conflicts of interest regarding this article exist. This article received no external funding. The authors wish to thank ...

\section{REFERENCES}

Aberbach, J. D., \& Christensen, T. (2005). Citizens and consumers: an NPM dilemma. Public Management Review, 7(2), 225-246.

Austin, J., Stevenson, H. \& Wei-Skillern, J. (2006). Social and commercial entrepreneurship: same, different, or both? Entrepreneurship Theory and Practice, 30(1), 1-22.

Blackwell, R. D., Miniard, P. W. \& Engel, J. F. (2003). Consumer behavior. Orlando: Dryden.

Bok, D. (2001). The trouble with government. Cambridge, MA: Harvard University Press. 
Bromley, D. B. (2000). Psychological aspects of corporate identity, image and reputation. Corporate Reputation Review, 3(3), 240-252.

Caruana, A. (2002). Service loyalty: the effects of service quality and the mediating role of customer satisfaction. European Journal of Marketing, 36(7/8), 811-828.

Ewing, M. T. \& Caruana, A. (2000). Marketing within the public sector. Journal of Nonprofit \& Public Sector Marketing, 8(1), 3-15.

Flyvbjerg, B. (2004). Phronetic planning research: Theoretical and methodological reflections. Planning Theory \& Practice, 5(3), 283-306.

Fountain, J. E. (2001). Paradoxes of public sector customer service. Governance, 14(1), 55-73.

Haig, B. D. (2005). An abductive theory of scientific method. Psychological Methods, 10(4), 371388

Harviainen, J. T. (2014). Service multipliers, service visibility. Design Management Review, 25(2), 28-33.

Hood, C. (1991). A public management for all seasons. Public Administration, 69(1), 3-19.

James, O., Jike, S., Petersen, C. \& Van de Walle, S. (2016). Citizens' blame of politicians for public service failure: experimental evidence about blame reduction through delegation and contracting. Public Administration Review, 76(1), 83-93.

Jobber, D. \& Lancaster, G. (2009). Selling and sales management, 8th ed. Harlow: Prentice Hall. Kelle, U. (2007). Development of categories: Different approaches in grounded theory. In Bryant, A \& Charmaz, K. (eds.), The SAGE handbook of grounded theory. 191-213.

Ketokivi, M. \& Choi, T. (2014). Renaissance of case research as a scientific method. Journal of Operations Management, 32, 232-240.

Kotler, P. \& Levy, S. J. (1971). Demarketing, yes, demarketing. Harvard Business Review, 49(6), 74-80.

Kvale, S. \& Brinkmann, S. (2014) Interviews: learning the craft of qualitative research interviewing, 3rd ed. Thousand Oaks: Sage. 
Lee, R. M. (1993). Doing research on sensitive topics. London: Sage.

Leenders, M. R., \& Blenkhorn, D. L. (1988). Reverse marketing: the new buyer-supplier relationship. New York, NY: Free Press.

Liu, B. H. \& Horsley, J. S. (2007). The government communication decision wheel: toward a public relations model for the public sector. Journal of Public Relations Research, 19(4), 377-393.

Magnani, L. (2001). Abduction, reason, and science: Processes of discovery and explanation. New York: Kluwer/Plenum Press.

Moncrief, W. C. \& Marshall, G. W. (2005). The evolution of the seven steps of selling. Industrial Marketing Management, 34(1), 13-22.

Moore, M. H. (1995). Creating public value: strategic management in government. Cambridge: Harvard University Press.

Normann, R. (2001). Service management: strategy and leadership in service business, 3rd ed. Chichester: Wiley.

Nutt, P. C. (2006). Comparing public and private sector decision-making practices. Journal of Public Administration Research and Theory, 16(2), 289-318.

Nutt, P. C. \& Backoff, R. W. (1993). Organizational publicness and its implications for strategic management. Journal of Public Administration Research and Theory, 3(3), 209-231.

O'Flynn, J. (2007). From new public management to public value: paradigmatic change and managerial implications. Australian Journal of Public Administration, 66(3), 353-366.

Oswald, L. R. (2015). Creating value: the theory and practice of marketing semiotics research. Oxford: Oxford University Press.

Parker, R., Kaufman-Scarborough, C. \& Parker, J. C. (2007). Libraries in transition to a marketing orientation: are librarians' attitudes a barrier?" International Journal of Nonprofit and Voluntary Sector Marketing, 12(4), 320-337.

Reichertz, J. (2007). Abduction: The logic of discovery of grounded theory. In Bryant, A \& Charmaz, K. (eds.), The SAGE handbook of grounded theory. London, Sage, pp. 214-228. 
Sarstedt, M. \& Schloderer, M. P. (2011). Developing a measurement approach for reputation of non-profit organizations. International Journal of Nonprofit and Voluntary Sector Marketing, 15(3), 276-299.

Schloderer, M. P., Sarstedt, M. \& Ringle, C. M. (2014). The relevance of reputation in the nonprofit sector: the moderating effect of socio-demographic characteristics. International Journal of Nonprofit and Voluntary Sector Marketing, 19(2), 110-126.

Stake, R. E. (2005). Qualitative case studies. In Denzin, N. K. \& Lincoln, Y. S. (eds.), The Sage handbook of qualitative research. Thousand Oaks, CA: Sage, pp. 443-466.

Van de Walle, S. (2016). When public services fail: A research agenda on public service failure. Journal of Service Management, 27(5), 831-846.

van Helden, J. \& Reichard, C. (2016). Commonalities and differences in public and private sector performance management practices: a literature review. In M. J. Epstein, F. Verbeeten \& S. K. Widener (eds.), Performance measurement and management control: contemporary issues (pp. 309-351). Bradford: Emerald.

Viio, P. \& Grönroos, C.. 2016. How buyer-seller relationship orientation affects adaptation of sales processes to the buying process. Industrial Marketing Management, 52, 37-46.

Walton, A. \& Hume, M. (2012). Examining public hospital service failure: the influence of service failure type, service expectations, and attribution on consumer response. Journal of Nonprofit and Public Sector Marketing, 24(3), 202-221.

Webster, F. E. \& Wind, Y. (1972). A General Model for Understanding Organizational Buying Behavior. Journal of Marketing, 36(April), 12-19.

Wilson, A., Zeithaml, V. A., Bitner, M. J. \& Gremler, D. D. (2006). Services marketing: integrating customer focus across the firm, First European Ed. London: McGraw-Hill. 